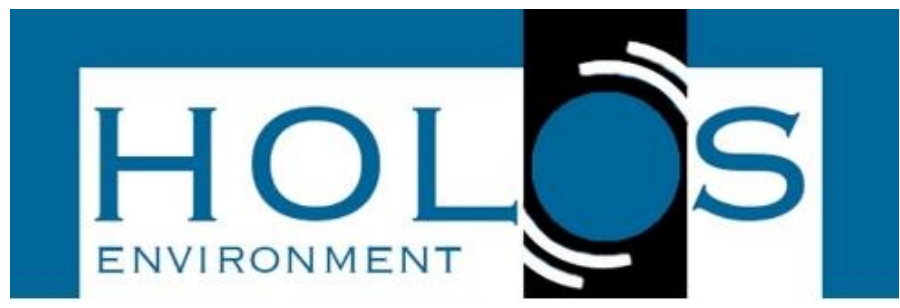

\title{
AVALIAÇÃO DE CENÁRIOS ECONÔMICOS HIPOTÉTICOS PARA VIABILIZAR O PAGAMENTO PELOS SERVIÇOS AMBIENTAIS - PSA
}

\section{HYPOTHETICAL ECONOMIC EVALUATION OF SCENARIOS TO FACILITATE THE PAYMENT FOR ENVIRONMENTAL SERVICES - PSA}

\author{
Edson Augusto dos Reis ${ }^{1}$; Adriana Maria Imperador ${ }^{2}$
}

Artigo recebido em: 24/11/2019 e aceito para publicação em: 08/01/2020.

DOI: http://dx.doi.org/10.14295/holos.v20i1.12363

Resumo: $O$ presente artigo organiza, avalia e discuti sobre cenários econômicos hipotéticos com objetivo de viabilizar o Pagamento pelos Serviços Ambientais - PSA providos pela bacia do ribeirão do Cipó, que é o manancial estratégico do Município de Poços de Caldas - MG. A organização e resultados deste estudo deu-se pela: (I) Avaliação dos aspectos conceituais, (II) Caracterização do uso e ocupação do solo que, dos 7.752 hectares de área da bacia hidrográfica: 30,2\% mata nativa, 29,3\% solo exposto, $23,8 \%$ cultivo de Eucalipto, $4,9 \%$ de água no reservatório e corpos d'água; (III) Avaliação da Disposição a Pagar - DAP onde, observou-se que $54 \%$ da população está disposta a pagar pelos serviços a um valor médio de $R \$ 6,43$; (IV) simulação de cenários econômicos hipotéticos onde, os cenários (1) e (3) ficam abaixo do custo de oportunidade enquanto que os Cenários (2) e (4) apresentam uma atratividade para os proprietários a montante.

Palavras-chave: Gestão de recursos hídricos. Uso e ocupação do solo. Disposição a Pagar. Viabilidade econômica. Poços de Caldas.

\begin{abstract}
The present paper organizes, evaluates and discusses hypothetical economic scenarios with the objective to promote the Payment for Environmental Services - PES provided by the Cipó River watershed, which is the strategic spring of the Municipality of Poços de Caldas - MG. The organization and results of this study were: (I) Evaluation of conceptual aspects, (II) Characterization of land use and occupation, where the 7,752 hectares of watershed area: $30.2 \%$ native forest, $29.3 \%$ exposed soil, 23.8\% Eucalyptus cultivation, 4.9\% water in the reservoir and body of water; (III) Assessment of the Willingness to Pay - AWP showed that $54 \%$ of the population is willing to pay for services at an average value of $R \$ 6,43$; (IV) simulation of hypothetical economic scenarios where the scenarios (1) and (3) are below the cost of opportunity while the scenarios (2) and (4) present attractiveness to upstream owners.
\end{abstract}

Keywords: Water resources management. Use and occupation of soil. Willingness to Pay. Economic viability. Poços de Caldas.

\footnotetext{
1 Universidade Federal de Alfenas (UNIFAL), Alfenas, MG. E-mail: (edson.reis@alcoa.com)

2 Instituto de Ciência e Tecnologia, Universidade Federal de Alfenas (UNIFAL), Campus Poço de Caldas, MG. Email: adrianaimperador@yahoo.com.br
} 


\section{INTRODUÇÃO}

\subsection{Contextualização}

As projeções de crescimento populacional associadas com o atual padrão de consumo e seus impactos sobre os recursos naturais e ecossistemas, apontam para um cenário desafiador para atual sociedade a níveis globais. Estima-se que a população mundial seja de nove bilhões de pessoas em 2043, aproximadamente dois bilhões a mais de pessoas no planeta do que os números atuais, sendo que destes, grande parte viverá em países com escassez de água.

O cenário para uma crise ambiental já é eminente e tem se acentuado principalmente devido ao crescimento populacional e a má utilização dos recursos naturais. O impacto das ações antrópicas gera externalidades com consequências diretas na qualidade e quantidade dos recursos naturais, em especial a água. Diante deste cenário, governos, universidades, instituições privadas e não governamentais, têm buscado por novas formas de planejar e gerir os recursos hídricos, buscando minimizar as consequências desta crise ambiental e garantir a continuidade do provimento destes serviços ambientais em condições sustentáveis nas perspectivas sociais, ambientais e econômicas.

As externalidades negativas desta crise ambiental no âmbito de recursos hídricos são ameaças ainda mais graves quando o corpo de água ou bacia hidrográfica em questão é um manancial de abastecimento urbano. No Brasil, apesar do grande volume de água disponível em algumas regiões, muitas vezes a água de qualidade é escassa e de difícil acesso, em especial nos grandes centros urbanos devido a características geográficas e densidade populacional. (ANA, 2013).

A reduzida precipitação registrada na região sudeste do Brasil no verão de 2013, associado aos baixos níveis registrados nos reservatórios e elevado consumo de água nos grandes centros para os mais diversos usos, trouxe à tona a contemporaneidade da preocupação da população com os conflitos de uso e riscos de desabastecimento.

Neste contexto, Poços de Caldas (MG) possui características singulares no que se refere à gestão de recursos hídricos, pois, além de um histórico de crescimento social e econômico fortemente ligado ao uso de suas águas, atualmente o município conta com um arranjo de gestão pública peculiar da água, com departamentos específicos ligados a gestão de água com departamentos específicos ligados a gestão de água e esgoto, produção de energia, comercialização de água mineral e de usos atrativos ao turismo.

A bacia do Ribeirão do Cipó foi escolhida como objeto deste estudo pela sua importância como manancial estratégico do município tanto nos aspectos quantitativos, responsável por $47 \%$ do sistema de captação de água da cidade, percentual que representa $8.232 .750 \mathrm{~m}^{3} /$ ano, quanto pelos aspectos da qualidade da água em função das características fisioquímicas e de ocupação e uso de solo de sua bacia (DMAE, 2013). 
Neste contexto pretende-se que aprofundar na análise deste arranjo peculiar de gestão, em cenário crítico de disponibilidade do recurso hídrico, confere uma oportunidade singular para avaliar de forma científica seus aspectos positivos e negativos, bem como, apontar oportunidades de aprimoramento deste modelo de gestão que pode vir a ser uma referência para outros municípios.

\subsection{Justificativa}

Apesar das diversas teorias e modelos econômicos já testados, segundo Pearce e Turner (1990) "a degradação ambiental é atribuída por uma falha crônica dos mercados para internalizar as externalidades" a luz da principal teoria que parte de uma perspectiva Econômica Ambiental Neoclássica. No médio e longo prazo, desconsiderar o valor dos serviços ambientais frente a grande pressão exercida pelo impacto do modelo econômico, sobre os ecossistemas é algo que tem sido preocupação de vários setores da sociedade (MOTTA, 1998).

Avaliar e valorar as externalidades ambientais decorrentes desta situação de estresse dos recursos hídricos é fundamental para fomentar e integrar políticas públicas de valoração que busquem internalizar as externalidades ambientais por meio da criação de um mercado de serviços ecossistêmicos segundo Pearce e Turner (1990). Conforme estabelece a Lei Federal 9.433/97 que dispõe sobre a Política Nacional de Recursos Hídricos - PNRH (BRASIL, 1997), é preciso reconhecer a água como um bem de domínio público e recurso natural limitado, dotado de valor econômico para encontrar um equilíbrio na relação oferta e procura de forma que a população tenha uma real percepção do valor da água.

Neste sentido, o presente artigo apresenta e propõe uma avaliação de cenários econômicos hipotéticos para viabilizar o Pagamento por Serviços Ambientais - PSA providos pela bacia hidrográfica como um instrumento econômico na gestão desta, uma vez que a cobrança pelo uso da água através do comitê de bacias hidrográficas ainda não foi implantada e por sua importância estratégia para o abastecimento da população deste município.

\section{MATERIAIS E MÉTODOS}

Para avaliar a viabilidade econômica do Pagamento pelos Serviços Ambientais - PSA da bacia do Ribeirão do Cipó, torna-se necessário a organização de diversas informações que possibilitem a organização dos cenários econômicos hipotéticos para facilitar a tomada de decisão por parte dos diversos atores e esferas institucionais. A metodologia utilizada neste artigo para levantamento destas informações deu-se pela seguinte ordem, como segue:

i. Avaliar os aspectos conceitos e legais aplicáveis aos Serviços Ecossistêmicos, Valoração dos Serviços Ambientais e Pagamento pelos Serviços Ambientais - PSA

ii. Caracterizar o atual uso e ocupação do solo da Bacia hidrográfica do Ribeirão do Cipó; 
iii. Avaliar a Disposição a Pagar - DAP da população Poços caldense pelos Serviços Ambientais providos pela bacia hidrográfica do Ribeirão do Cipó;

iv. Estabelecer e simular diferentes cenários econômicos hipotéticos de Pagamento pelos Serviços Ambientais - PSA providos pela bacia hidrográfica do Ribeirão do Cipó;

Por fim, avaliar a viabilidade econômica do pagamento pelos Serviços Ambientais a partir dos resultados obtidos e discutir as oportunidades e benefícios do PSA como instrumento de gestão dos recursos hídricos.

\subsection{Contextualização Conceitual e Legal}

Há muito tempo já se discute sobre a importância dos serviços ecossistêmicos, porém, apenas a partir da década de 1970, estudos mais aprofundados começaram a avaliar as interações e atribuir valores econômicos a estes serviços juntamente com o crescimento da preocupação relacionada com os impactos da ação humana sobre os recursos naturais e ecossistemas (WESTMAN, 1977 apud STANTON, TEIJERO, 2014, p.15).

Para Wallace (2007), não é apenas uma questão semântica, mas, essencial para chamar a atenção e guiar decisões sobre planejamento e gerenciamento de políticas a respeito dos recursos naturais. Aprofundando no conceito Boyd e Banzhaf (2007), definiram os serviços ecossistêmicos como "Finais" e "Intermediários" e chamaram a atenção para fato de que somente os Serviços Ecossistêmicos finais são "componentes da natureza diretamente aproveitada, consumida ou utilizada no campo do bem estar dos seres humanos", devendo estes, serem priorizados para o desenvolvimento de valoração. Por outro lado, Fisher e Turner (2008), afirmam que os serviços intermediários, como o sequestro de carbono, são também importantes pelos benefícios proporcionados aos seres humanos mesmo que de forma indireta.

A relação entre os Serviços dos Ecossistemas e o Bem-Estar humano é apresentada através da Figura 1, onde, a intensidade das cores e largura das setas representa graficamente a força entre as ligações e principais relações dos SE com os componentes do bem-estar humano (AEM, 2005).

Na Figura 1, o alto potencial de mediação pelos fatores socioeconômicos e forte ligação com os componentes básicos para o bem-estar humano, como os Serviços Ambientais de provisão, entre eles: Alimentos, água potável, madeira, fibra e combustíveis. A literatura apresenta publicações com o termo Pagamentos por Serviços Ecossistêmicos e para Pagamento por Serviços Ambientais, Andrade e Fasiaben (2009) apud Lima (2013) p. 2 consideram estes como sinônimos. Para fins de metodologia e padronização, adotou-se o termo Pagamento por Serviços Ambientais - PSA que é aplicado pela ANA (Agência Nacional de Águas).

Valorar economicamente os Serviços Ambientais tem sido objeto de estudos na busca de internalizar as externalidades destes serviços no modelo econômico. Nesta linha, Costanza et al. (1997) estimou que o valor total dos ecossistemas da terra poderia ser maior que a soma do produto bruto de todos os países. Aprofundando a análise dos modelos de valoração, concentrar os modelos através de uma visão 
antropocêntrica associada ao modelo econômico neoclássico ou por uma visão ecocêntrica associada a fluxos biogeoquímicos.

Figura 1 - Fluxo da relação dos SE com Bem-Estar humano

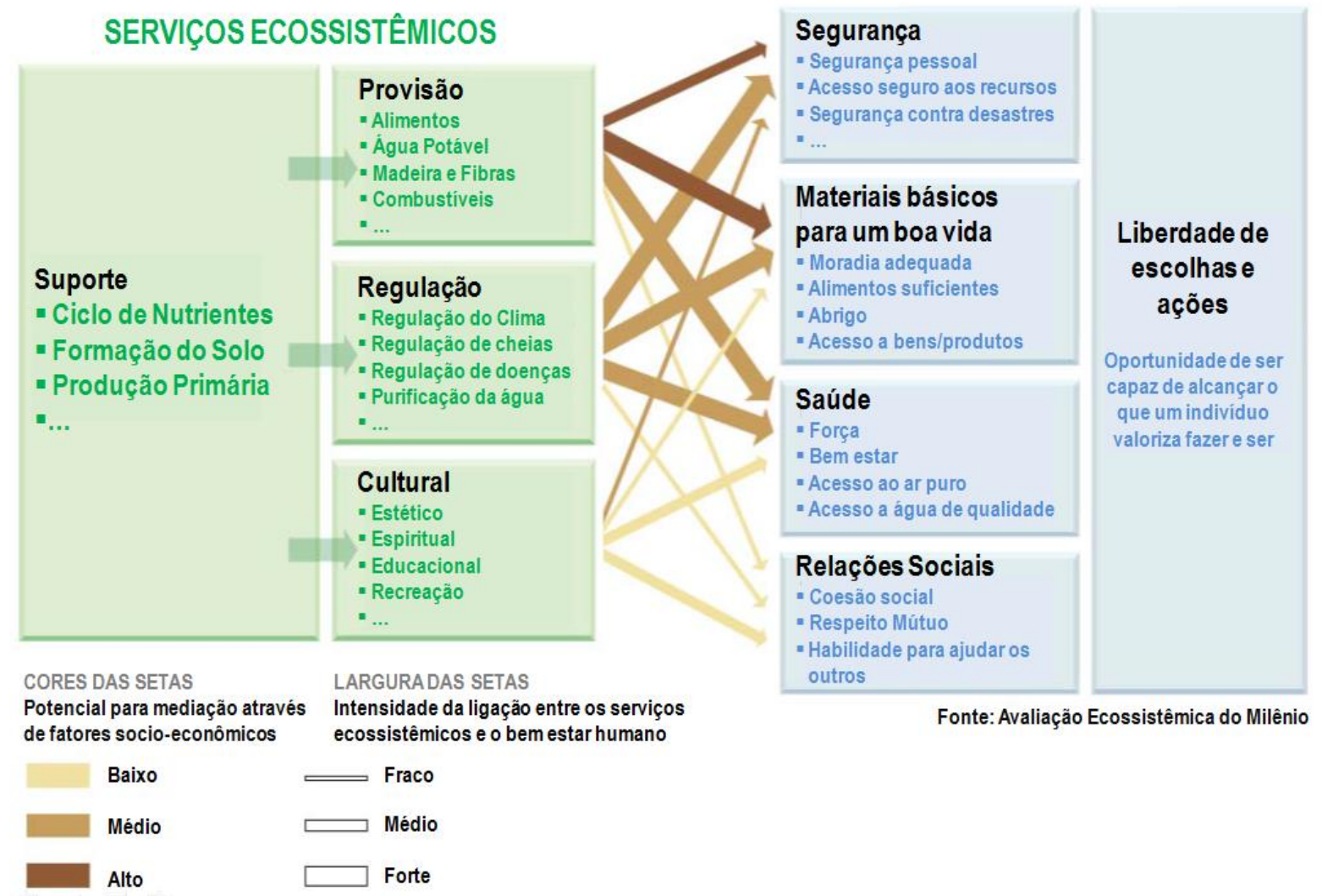

Fonte: Traduzido da Avaliação Ecossistêmica do Milênio (AEM, 2005)

Na Perspectiva Econômica da valoração, em linhas gerais o termo economia pode ser definido como "o estudo das maneiras de gerir os recursos" ou "a produção e a permuta de bens e serviços". A relação dos aspectos econômicos e suas influências na sociedade podem ser notadas no histórico das mais diversas civilizações, porém, o estudo na prática é relativamente novo. Os primeiros registros sobre temas econômicos foram manifestações de filósofos e políticos na Grécia antiga. Entretanto, apenas no século XVIII surgiram os primeiros economistas. Deste período, a publicação em 1776 do livro A Riqueza das nações de Adam Smith pode ser referenciada como um marco para a economia moderna (KISHTAINY, 2012).

A publicação da Avaliação Ecossistêmica do Milênio ONU em 2000 foi como um marco na arena política sobre o tema de serviços ecossistemas e valoração. Neste mesmo período a valoração da Biodiversidade ganha espaço com a publicação do relatório do The Economics of Ecosystems and Biodiversity - TEEB da (UNEP,2013).

A Disponibilidade a Pagar - DAP foi uma das etapas fundamentais para 0 sucesso do Métodos de Valoração Contingente - MVC, pois, dependendo da abordagem das estimativas o resultado pode ser diferente da realidade. Neste sentido, 
segundo Motta (1998) a literatura tem-se preferido DAP como uma mensuração conservadora.

O Pagamento por Serviços Ambientais - PSA é um instrumento com exemplos já implantados e operando em várias partes no mundo. A cidade de Nova York nos Estados Unidos assim como a cidade de Munique na Alemanha demandam uma grande quantidade de água de qualidade para suas populações, de 9 e 1,2 milhões de pessoas respectivamente. Ambas sofreram uma queda considerável na qualidade da água nos anos 1980 o que levou a necessidade de investimentos consideráveis nos sistemas de tratamento. No caso de Nova York estes investimentos eram na ordem de 6 bilhões de dólares ou mudanças no uso do solo deveriam ocorrer nas respectivas bacias hidrográficas. Para ambos os casos, contratos com proprietários de terra e fazendeiros a montante da cidade foram estabelecidos, porém, estes se diferenciavam em números e formas de compensação devido a diversos fatores socioeconômicos. (GROLLEAU e MACCANN, 2012).

Outro importante e recente exemplo na China. A cidade de Shiyan tem sido objeto de estudos no contexto de pagamentos por Serviços Ambientais com na gestão de recursos hídricos em função de sua importância a montante da bacia em função do projeto "South-to-North Water Diversion in China". Este projeto que objetiva transferir água do sul da China para o norte, é um dos maiores projetos de transposição de águas do mundo. Logo, aspectos regulatórios assim como critérios de cálculos para os custos do serviço de provisão de águas vêm sendo discutido. (DONG et al., 2011). Também exemplos em outros países como a Costa Rica, México, Madagascar, Tibet e Brasil.

O PSA pode ser definido em linhas gerais como um instrumento econômico que busca internalizar ao modelo econômico as externalidades ambientais através dos Serviços Ambientais. Esta abordagem representa uma mudança de paradigma e uma nova abordagem na gestão ambiental.

Segundo Wunder (2008), sob certas circunstâncias o PSA cria um mercado paralelo para tratar as questões ambientais, pode ser considerado como mais eficiente e eficaz do que as alternativas que não são de mercado, como: Regulamentação do governo através de ações de comando e controle, ações voluntárias da comunidade incentivadas pelo governo ou abordagens educacionais.

Wunder, Engel e Pagiola et al. (2008) ressaltam que o foco explícito nas externalidades positivas do PSA, traz uma nova abordagem de PBP - Princípio do Beneficiário Pagador ao invés do Princípio do Poluidor Pagador - PPP que já é mais conhecido. Os autores citam: "o proprietário de terra passa a ser visto agora, não como um poluidor, mas como um provedor de serviços a quem é apresentada a oportunidade de adicionar os serviços ambientais para seu portfólio de produção".

Hecken, Bastianensen e Vásquez (2012) apontam para algumas críticas na perspectiva política para os esquemas de PSA pelo fato da distribuição dos pagamentos possuírem uma interdependência no que se refere à eficiência e aos princípios de equidade. Os autores caracterizam os modelos como foco na distribuição dos recursos aos fornecedores como primeira geração de esquemas de PSA e 
apontam para a necessidade de uma nova geração com foco na eficiência e equidade da distribuição dos recursos.

No Contexto Nacional, entre as oportunidades identificadas nos programas e projetos, destaca-se uma dependência de recursos externos a economia das bacias ou dos municípios onde estão inseridos para manutenção dos programas Marco Regulatório sobre PSA (2012).

Segundo Tejeiro, Stanton (2014) a complexidade das interações que resultam na provisão dos Serviços Ambientais que associadas à ausência de foco e da falta de indicadores de desempenho para os projetos e programas, comprometem a análise da eficácia destes.

\subsection{Caracterizar o atual uso e ocupação do solo da bacia}

Esta pesquisa delimitou sua área de abrangência na bacia hidrográfica do Ribeirão do Cipó, seguindo orientação preconizada pelo Política Nacional de Recursos Hídricos, de adotar uma bacia hidrográfica como unidade territorial para gestão dos recursos hídricos (BRASIL, 1997). A localização desta área de estudo pode ser observada na Figura 2. Esta área de estudo compreende o manancial do município de Poços de Caldas no estado de Minas Gerais para abastecimento de água potável, regularização da vazão das demais bacias para a geração de energia, uso industrial, agroindustrial, além da manutenção dos níveis dos reservatórios e vazão dos rios para volume de água nas cachoeiras que são atrativos turísticos do município. Este Ribeirão é afluente do Rio das Antas, que deságua no Rio Pardo e que por sua vez faz parte da Bacia Hidrográfica do Rio Grande - BHRG dentro da Unidade de Planejamento e Gestão de Recursos Hídricos dos Afluentes dos Rios Mogi-Guaçu e Pardo GD6.

Figura 2 - Localização e delimitação da área de estudo

Localização da area de estudo

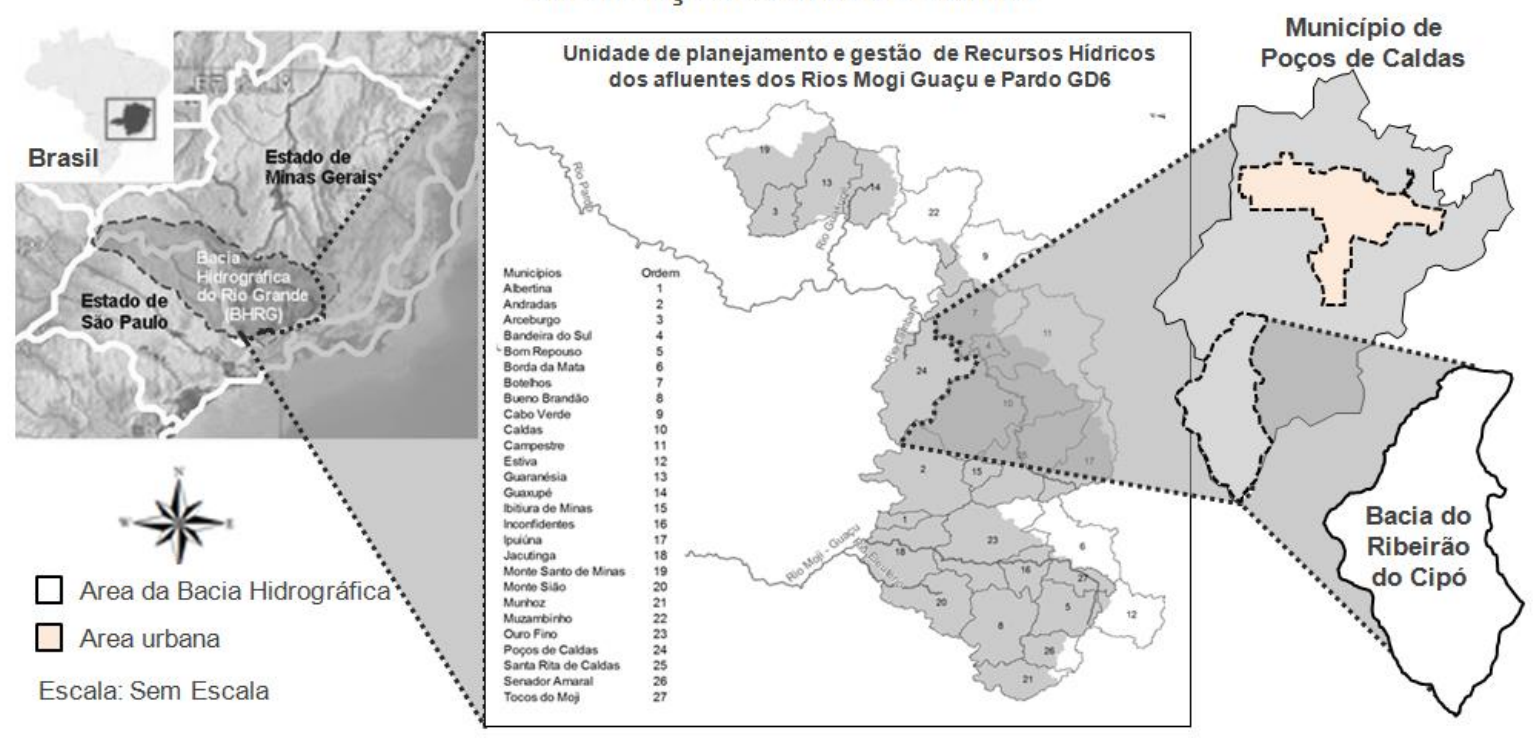

Fonte: Organização realizada pelo pesquisador (CBH Mogi/Pardo, 2014), (PMP, 2014) 
Com base no Plano Diretor de Saneamento do município, a bacia do Ribeirão do Cipó possui o manancial estratégico do município, responsável por $47 \%$ da água utilizada para abastecimento urbano (aproximadamente $8.232 .750 \mathrm{~m}^{3} / \mathrm{ano}$ ), pela manutenção da capacidade da Barragem do Ribeirão do Cipó. O Plano Diretor de Saneamento do município, ressalta que os mananciais próximos ao centro urbano do município de Poços de Caldas, em particular o reservatório do Cipó, são suficientes para o abastecimento da cidade até o ano de 2033 (DMAE, 2014).

Além da importância do uso da água como atrativo turístico, Poços de Caldas e o município de ljuí-SC são os únicos concessionários municipais de serviços públicos federais de energia elétrica no país. Em Poços de Caldas, segundo o Departamento Municipal de Eletricidade - DME o fornecimento de energia elétrica alcança hoje $100 \%$ da população. (DME, 2013).

Para a caracterização fisiográfica mais atualizada do uso e ocupação do solo na bacia do Ribeirão do Cipó, informações de geoprocessamento foram consideradas a partir dos resultados da interpretação de imagens de satélite obtidas na base de dados do Instituto Nacional de Pesquisa Espacial - INPE a partir das informações do satélite LANDSAT 7 referentes ao dia 01/09/2013. (INPE 2013).

Através do projeto de geoprocessamento proposto, identificou-se na área de 7.752 ha da bacia as seguintes classes de uso do solo: Matas $30,2 \%$, solo exposto $29,3 \%$, florestas comerciais de eucaliptos $23,8 \%$, áreas de campos naturais com vegetação de cerrado $11,8 \%$ e 4,9\% de água verificada através dos corpos d'água e do reservatório da Represa Lindolpho Silva Dias ou represa do Cipó conforme Figura 3 que apresenta o Mapa de Uso e Cobertura do Solo da Sub Bacia Ribeirão do Cipó Poços de Caldas MG.

Os resultados apontam para uma área de características rurais com pouquíssimas residências. As áreas caracterizadas como matas, são em sua grande parte de ocupação, áreas de mata ripária e acompanham os corpos d'água.

Uma grande área da bacia apresenta características de solo exposto, seguido de uma grande área como predominância do cultivo de florestas comerciais de eucalipto. Considerando que a imagem foi capturada no mês de setembro de 2013 , a primeira hipótese aponta para ocupação de atividades agrícolas. Uma segunda hipótese complementar é o uso do solo em algumas áreas para atividades de mineração.

O ponto que mais chama a atenção é a somatória da área ocupada por florestas comerciais de eucaliptos e solo exposto e/ou área agrícola, totalizando $53,1 \%$ da área da bacia que é o manancial do município.

Em estudo anterior na bacia do Ribeirão do Cipó, a partir da classificação de uma imagem gerada pelo satélite Landsat $7 \mathrm{ETM}$, referente a outubro de 2000. O autor também chama a atenção para áreas de reflorestamento com espécies de eucaliptos e pinheiros e destaca que esta "prática que deve ser bem controlada de modo que seu manejo não interfira no ecossistema local". (ALBERTI 2008).

Conforme concluído por Mattos (2009) a forma de manejo e conservação do solo é fundamental para o aumento da produção de água na bacia hidrográfica, logo, 
é importante avaliar de forma sistêmica o uso do solo no manancial com vistas para a produção de água.

Figura 3 - Mapa de Uso e Cobertura do Solo da Bacia Ribeirão do Cipó - Poços de Caldas

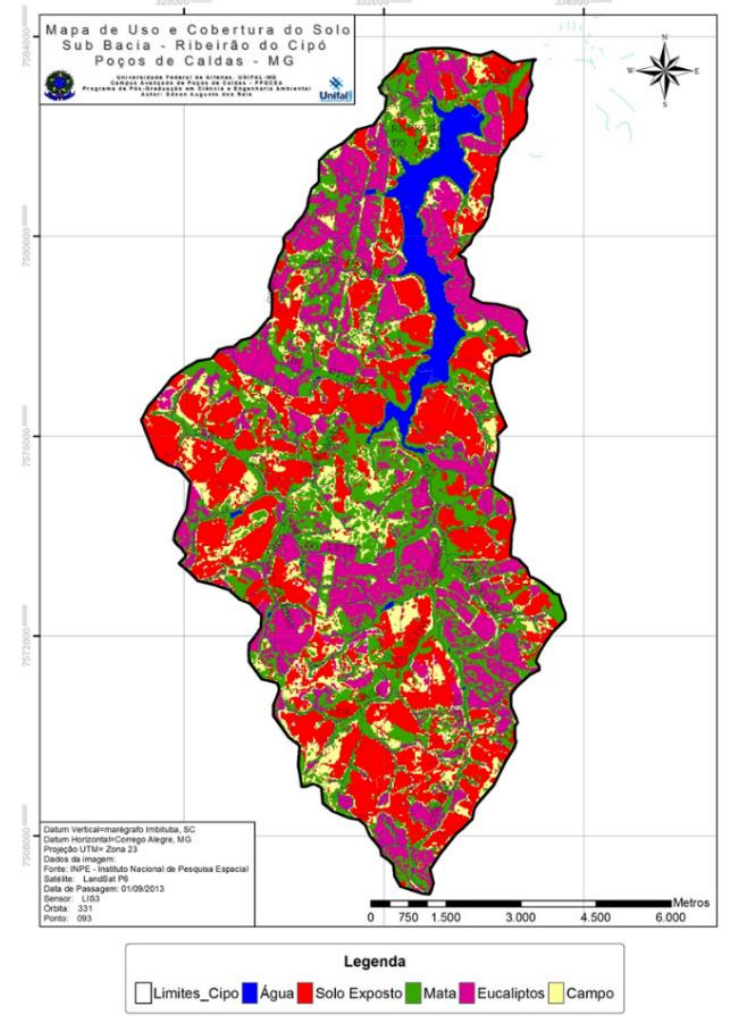

Fonte: Mapa organizado pelo autor como resultado da Dissertação de Mestrado

\subsection{Avaliação da Disposição a Pagar - Dap da População}

A fim de avaliar a sustentabilidade do modelo de gestão dos recursos hídricos, tomou como base os três vetores para o desenvolvimento sustentável ou Triple Bottom Line para estruturação da pesquisa. Este princípio aponta para o fato da sociedade depender da economia e a economia depender dos ecossistemas globais, sendo, o equilíbrio entre estes vetores uma indicação para um modelo sustentável. Entretanto, este não é um processo estável, estando sim em constante fluxo devido a pressões sociais, políticas, econômicas e ambientais assim como ciclos e conflitos (ELKINGTON, 1998).

A metodologia empregada na avaliação da Disposição a Pagar - DAP da população poços caldense, considerou para o tamanho da amostra, estimativa conforme metodologia para populações finitas propostas por Gil (2008), Considerando um nível de confiança de $95,5 \%$ ou 2 desvios padrão, um percentual de ocorrência do fenômeno máximo de $50 \%$, assim como $50 \%$ de porcentagem complementar e por ultimo uma taxa de erro de $5 \%$ conforme intervalo de erros usualmente utilizados em pesquisas e estudos sociais, teve com produto uma amostra de 335 indivíduos. A estratificação das amostras foi feita a partir das sete Áreas de Ponderação - AP 
estabelecidas pelo IBGE e adotados no Plano Diretor do município. As 335 amostras foram dividas e estratificadas pelos bairros urbanos conforme Plano Diretor do Município de Poços de Caldas, 2006.

Aprovado a pesquisa seguindo as diretrizes do Conselho Nacional de Saúde que considera que "pesquisas com seres humanos aquelas realizadas em qualquer área do conhecimento" (CNS, 1996), foi aberto processo específico para a pesquisa e encaminhado para apreciação do Comitê de Ética da UNIFAL-MG, sendo aprovado conforme parecer consubstanciado com número: 445.731 provido pela relatoria, em 04/11/2013.

Conforme propõe Gil (2008) utilizou-se do método de entrevistas estruturadas, onde, um questionário com 14 perguntas fixas foi utilizado para abordar características socioeconômicas, aspectos ambientais e a disposição a pagar DAP dos entrevistados para proteger os recursos hídricos da bacia em estudo. O questionário utilizado contém perguntas para identificar características socioeconômicas dos entrevistados e a DAP pelos Serviços Ambientais providos pelo manancial. Foi adaptado do modelo utilizado por Machado (2011) em sua dissertação sobre "Valoração econômica dos recursos hídricos da bacia hidrográfica do manancial do Ribeirão do Feijão São Carlos $S P$ ". Foram modificados os valores da questão 06 , com base no salário mínimo e incluso as perguntas 08 e 09 referentes à ocorrência e frequência da falta de água na residência dos entrevistados.

\subsection{Estabelecer e Simular Cenários Econômicos Hipotéticos}

Para estruturar os cenários, o principio econômico da Oferta e Procura foi à base para definir as partes interessadas e papeis envolvidos. É importante balancear e buscar equilíbrio de benefícios para ambos os papeis, sendo que os proprietários de terras do manancial são considerados nesta avaliação como os provedores dos serviços ambientais hídricos, enquanto que os usuários dos recursos hídricos ligados diretamente ao manancial serão os usuários, enquadram-se neste lado da balança a população e aqueles empreendimentos devidamente outorgados para uso significativo dos recursos hídricos do município.

Como o cultivo de florestas de eucalipto é predominante na área delimitada para este estudo e este tem sido atrativo economicamente na região frente ao outras culturas, simularemos o custo de oportunidade para os proprietários, através da extrapolação do cultivo de eucaliptos para toda a área de solo exposto adicionalmente a área já cultivada.

O custo de oportunidade é um principio muito utilizado na área econômica de avaliação das possibilidades de criação de valor e riscos equivalentes e na área contábil para simulação, avaliação e aplicação de resultados. Revisões bibliográficas sobre o tema apontam a autoria da expressão para Frederich Von Wieser, um economista austríaco que definiu o custo de oportunidade como: "a renda líquida gerada pelo fator (de produção) em seu melhor uso alternativo". Pressupõe que a melhor alternativa seja viável e existente, para que o proprietário possa realizar uma decisão efetiva sobre seu empreendimento, pois, logo que tomada esta decisão, 
acarretará o sacrifício ou abandono de outras que não foram escolhidas (GOULART, 2002).

Para viabilizar analises e comparações com os resultados obtidos por Machado (2011) na bacia do Ribeirão do Feijão no município de São Carlos - SP, o Cenário 01 foi definido a partir da mesma metodologia utilizada, demandando o uso das ferramentas de Matemática Financeira VPL - Valor Presente Liquido, VPLA - Valor Presente Líquido Anual e Atualização Monetária através do Índice Nacional de Preços ao Consumidor Amplo - IPCA.

O plantio florestal de eucaliptos tem crescido em função de sua atratividade econômica frente a outras atividades agropecuárias. O retorno financeiro e a demanda por madeira para diversos fins têm feito desta atividade uma das mais rentáveis no meio rural segundo informações da EMBRAPA. (EMBRAPA, 2014).

Uma das características fundamentais para a análise de cenários financeiros e aplicação de ferramentas como VPL é adequação e correção dos valores para uma mesma data. Logo, a atualização monetária dos valores deste estudo foi realizada para adequar todos os valores para o período de maio de 2014. Os valores anualizados do IPCA - Índice Nacional de Preços ao Consumidor Amplo que é o mais utilizado para as políticas e ações macroeconômicas e referência para os mercados foram utilizados como segue: para $2014=3,45$; para $2013=5,91$; para $2012=5,88$ e para $2011=6,50$. (IBGE 2014).

A partir das variáveis apresentadas e devidos ajustes e correções monetárias, calculou-se o custo de oportunidade dos produtores com a premissa de que a melhor alternativa viável para uso e ocupação do solo seria o com o cultivo de florestas de eucalipto em detrimento de outras culturas. Logo, a rentabilidade máxima obtida por hectares é de $R \$ 1.642,00$ ao ano e para toda a área cultivada da bacia de $R \$$ 6.758.472,00 ao ano, base 2014. Portanto, se os proprietários decidirem por outra atividade nas áreas deste estudo, o custo de oportunidade deverá ser avaliado a partir dos valores apresentados acima para avaliar a viabilidade de outros empreendimentos. Ou seja, delimitando a analise para o objeto em estudo, o PSA só será viável em linhas gerais para os proprietários e produtores quando os valores monetários por hectare forem maiores que o custo de oportunidade de $R \$ 1.642,00$ ao ano.

Os cenários a seguir são simulações hipotéticas para algumas possibilidades de arranjo para a cobrança do uso da água no município e para implantação do Pagamento por Serviços Ambientais Hídricos. Entre as premissas está a utilização e aplicação dos recursos obtidos na bacia e também a tentativa de internalizar o montante necessário para implementação do PSA no município a valores atrativos tanto para os provedores dos serviços ambientais hídricos quanto para os usuários dos recursos hídricos no município.

O Cenário 01 considera variáveis apresentadas nos Capítulos 3 e 4 para o uso e ocupação do solo da bacia e DAP da média da população poços caldense respectivamente, além de algumas comparações com resultados obtidos no município de São Carlos-SP. O Cenário 02 considera uma simulação de rateio realizado a partir das Outorgas deferidas atualmente no Município. O Cenário 03 simula a cobrança da 
água para as Outorgas deferidas no modelo já implantado da bacia do rio das Velhas

no estado. Por fim, o Cenário 04, internaliza o custo de oportunidade nos demonstrativos de resultados do Departamento Municipal de água e esgoto - DMAE, Departamento Municipal de Energia - DME e o montante do somatório dos resultados destes a partir do Exercício Contábil de 2013.

\section{RESULTADOS E DISCUSSÃO}

\subsection{Cenário 01 - comparação entre DAP média e custo de oportunidade}

A elaboração deste cenário tem objetivo avaliar os valores obtidos na Disponibilidade a Pagar - DAP média da pesquisa, extrapolada para a população (domicílios) do município versus o custo de oportunidade dos produtores, conforme metodologia. Nesta mesma linha de análise utilizada por Machado (2011) em pesquisa no município de São Carlos - SP, quando comparou os resultados da DAP com a análise do lucro máximo anual das áreas cultivadas do manancial do Ribeirão do Feijão. Os resultados obtidos na pesquisa e corrigidos em Poços de Caldas e comparado a de São Carlos, aplicando a correção monetária são respectivamente: $\mathrm{R} \$$ 6.758.000 / Ano de Custo de Oportunidade, versus, $R \$$ 5.051.000/Ano de DAP da População para Poços de Caldas - MG e R\$15.536.000 / Ano de Custo de Oportunidade, versus, R\$9.489/Ano de DAP da População de São Carlos - SP pelos valores corrigidos a partir do IPCA. Nas duas situações, o montante dos os valores da Disponibilidade a Pagar pelos serviços ambientais hídricos extrapoladas para toda a população é menor do que o custo de oportunidade dos proprietários. Observa-se uma defasagem de $25 \%$ nos resultados de Poços de Caldas e de $39 \%$ para São Carlos. Vale ressaltar que os valores absolutos são diferentes, devido a diferença na população onde Poços de Caldas aproximadamente 150.000 e São Carlos 250.000 habitantes. Adicionalmente, a área produtiva do manancial do Ribeirão do Feijão avaliada no estudo em São Carlos representa $12,88 \%$ do município, enquanto que a mesma análise para o caso do manancial do Ribeirão do Cipó, a área produtiva é menor que $1 \%$ do município de Poços de Caldas. Os valores absolutos obtidos possibilitaram algumas informações comparativas, porém, para relativizar as informações e permitir melhor comparação, foi realizada as devidas correções monetárias para dos resultados obtidos em São Carlos 2011.

Os mesmos resultados anualizados, porém, com valores por hectares apresentam respectivamente: $R \$ 1.642$ ao Ano de Custo de Oportunidade, versus, $R \$$ $1.227,3$ ao ano de DAP Média da População para Poços de Caldas - MG e R\$ $1.126,00$ ao Ano de Custo de Oportunidade, versus, $R \$ 687,77$ ao ano de DAP Média da População de São Carlos - SP.

Nota-se uma mudança de dimensão para os cenários, onde, tanto o custo de oportunidade quanto os valores de PSA pela DAP estão agora maiores em Poços de Caldas. O maior valor de DAP nesta análise por hectare está ligada as DAPs médias de $\mathrm{R} \$ 6,43$ e $\mathrm{R} \$ 3,79$ obtidas respectivamente em Poços de Caldas e São Carlos. Os valores utilizados na base de Custo de Oportunidade dos produtores foram os 
principais motivos para a os resultados, pois, a ocupação predominante do manancial de Poços de Caldas por florestas de eucalipto, levou a consideração exclusiva desta cultura para cultivo, enquanto que para o manancial de São Carlos a ocupação do solo apresentou também culturas de cana-de-açúcar, laranja e pastagem.

\subsection{Cenário 02 - rateio do custo de oportunidade pela cobrança pelo uso da água}

A partir do custo de oportunidade total para os produtores da bacia de $\mathrm{R} \$$ 6.758.000,00 por ao ano, o Cenário 02 propõe o rateio deste valor através da cobrança dos usuários significativos do município, com outorgas deferidas em dezembro de 2011 e com validades previstas para os períodos de 2014, 2015 e 2016.

Nota-se que $98,59 \%$ do volume de água outorgado no município destina-se para a geração de energia, o que impacta consideravelmente os resultados deste cenário. As diretrizes da Agência Nacional de Energia Elétrica - ANEEL que regula entre outras questões a compensação financeira pela utilização de recursos hídricos para geração de energia elétrica no Brasil, aponta para a isenção da compensação financeira para as usinas com capacidade instalada de no máximo $30 \mathrm{MW}$, denominadas Pequenas Centrais Hidrelétricas - PCHsa (ANEEL, 2005). Devido às características destes empreendimentos de geração de energia do volume de produção, seria necessário desconsiderá-los deste tipo de cobrança.

Neste cenário, o valor unitário em $R \$$ por $m^{3}$ de água utilizada é de $R \$ 0,75$, um valor muito alto para os usuários frente ao que vem sendo utilizado em outras bacias com cobrança pelo uso da água já implantada no estado. Como base de comparação, os valores de cobrança para Captação Superficial e Subterrânea na Bacia do Rio das Velhas é de $\mathrm{R} \$ 0,01 / \mathrm{m}^{3}$.

\subsection{Cenário 03 - simulação da cobrança no modelo implantado na bacia do rio das velhas}

Neste cenário, extrapolou-se o volume outorgado para águas superficiais e subterrâneas de Poços de Caldas em dezembro de 2011 para uma base de captação anual hipotética de $47.217 .427 \mathrm{~m}^{3}$. Logo, este valor foi lançado no simulador de cobrança pelo uso da água da bacia do rio das Velhas em Minas Gerais obtidos desta simulação em planilha de cálculo disponibilizada pelo IGAM. (IGAM, 2014).

O valor obtido nesta simulação foi de um pagamento de $R \$ 1.416 .522,82$ pelo uso da água no ano, confrontando com o valor do custo de oportunidade total para os produtores da bacia de $\mathrm{R} \$ 6.758 .000,00$ por ano. Estes cenários apresenta um percentual de $79 \%$ de defasagem entre a arrecadação frente ao custo de oportunidade.

\subsection{Cenário 04 - internalizando o PSA nos departamentos municipais}

O Cenário 04 limita-se a uma avaliação financeira superficial do impacto de uma possível absorção do custo de oportunidade dos proprietários através do PSA 
frente aos demonstrativos de resultados dos exercícios findos de 2013, publicados pelos Departamentos Municipais de Água/Esgoto e Energia. O Objetivo deste cenário é avaliar o impacto percentual e significância em termos de valores nos resultados destes departamentos, para que o Custo de Oportunidade dos proprietários seja absorvido pela estrutura dos mesmos. Parte-se da hipótese de que estes departamentos poderiam gerenciar mais facilmente o arranjo necessário para a implantação da cobrança pelo uso da água e PSA no município através da sinergia da atual estrutura e ganhos de produtividade.

Os números de 2013 informações de receita operacional e resultados do ano de 2013 publicadas pelo Departamento Municipal de Energia - DME e pelo Departamento Municipal de Água e Esgoto - DMAE apresentam resultados positivos tanto para o DME com lucro verificado $R \$ 10,01$ milhões o equivalente a $7,3 \%$ da receita e quanto para o DMAE o Superávit foi de $R \$ 8,10$ milhões o equivalente a $18,7 \%$ da receita. Estes resultados concentram em nível exploratório e preliminar para discussão. Vale salientar, que não foi considerado nestas simulações nenhuma avaliação de cálculo ou ajustes de ordem financeira, contábil e tributária, e que estes podem sofrer alterações devido a variáveis de origem econômica. O objetivo em linhas gerais foi simular a absorção dos Custos de Oportunidade para os proprietários do manancial do Ribeirão do Cipó para PSA e avaliar o impacto destas nos resultados DME e DMAE para iniciar uma discussão preliminar, já com aprofundamento das análises financeiras, contábeis e tributárias a serem avaliadas em mais detalhes.

Tabela 1 - Cenários hipotéticos de resultados em milhares de reais para o Departamento Municipal de Energia- DME e Departamento Municipal de Água e Esgoto- DMAE de Poços de Caldas - MG com a absorção dos Custos de Oportunidade para os proprietários do manancial do Ribeirão do Cipó para PSA

\begin{tabular}{|c|c|c|c|c|c|c|c|c|}
\hline \multicolumn{9}{|c|}{ Cenários Hipotéticos para Demonstrativo de Resultados - DME e DMAE de Poços de Caldas - MG } \\
\hline \multirow[t]{2}{*}{ Descrição } & \multicolumn{2}{|c|}{\begin{tabular}{|c|} 
DME \\
Exercício de 2013
\end{tabular}} & \multirow[t]{2}{*}{ Descrição } & \multicolumn{2}{|c|}{\begin{tabular}{|c|} 
DMAE \\
Exercício de 2013
\end{tabular}} & \multirow[t]{2}{*}{ Descrição } & \multicolumn{2}{|c|}{$\begin{array}{c}\text { DME + DMAE } \\
\text { Exercício de } 2013\end{array}$} \\
\hline & $\mathrm{RS}$ & $\%$ & & $\mathrm{RS}$ & $\%$ & & $\mathbf{R S}$ & $\%$ \\
\hline Receita Operacional & 137.245 & $100,0 \%$ & Receita Operacional & 43.398 & $100,0 \%$ & Receita Operacional & 180.643 & $100,0 \%$ \\
\hline Custo de Oportunidade & 6.758 & $4,9 \%$ & Custo de Oportunidade & 6.758 & $15,6 \%$ & Custo de Oportunidade & 6.758 & $3,7 \%$ \\
\hline Lucro/Prejuizo ajustado & 3.252 & $2,4 \%$ & Superávit/Défict Ajustado & 1.338 & $3,1 \%$ & Superávit/Défict Ajustado & 11.348 & $6,3 \%$ \\
\hline
\end{tabular}

Os dados tabulados destes cenários e seus resultados nas simulações também podem ser observados nas Figuras: 7, 8 e 9 que demonstram o impacto para o DME, DMAE e a soma entre DME e DMAE respectivamente. Nota-se nesta analise superficial que a partir dos Resultados de 2013, nas três situações, o custo de oportunidade pode ser absorvido sem causa prejuízo ou déficit para os departamentos municipais de água e energia. 
Figura 4 - Cenário hipotético de absorção do Custo de Oportunidade dos produtores pelo DME para PSA do manancial estratégicos de Poços de Caldas

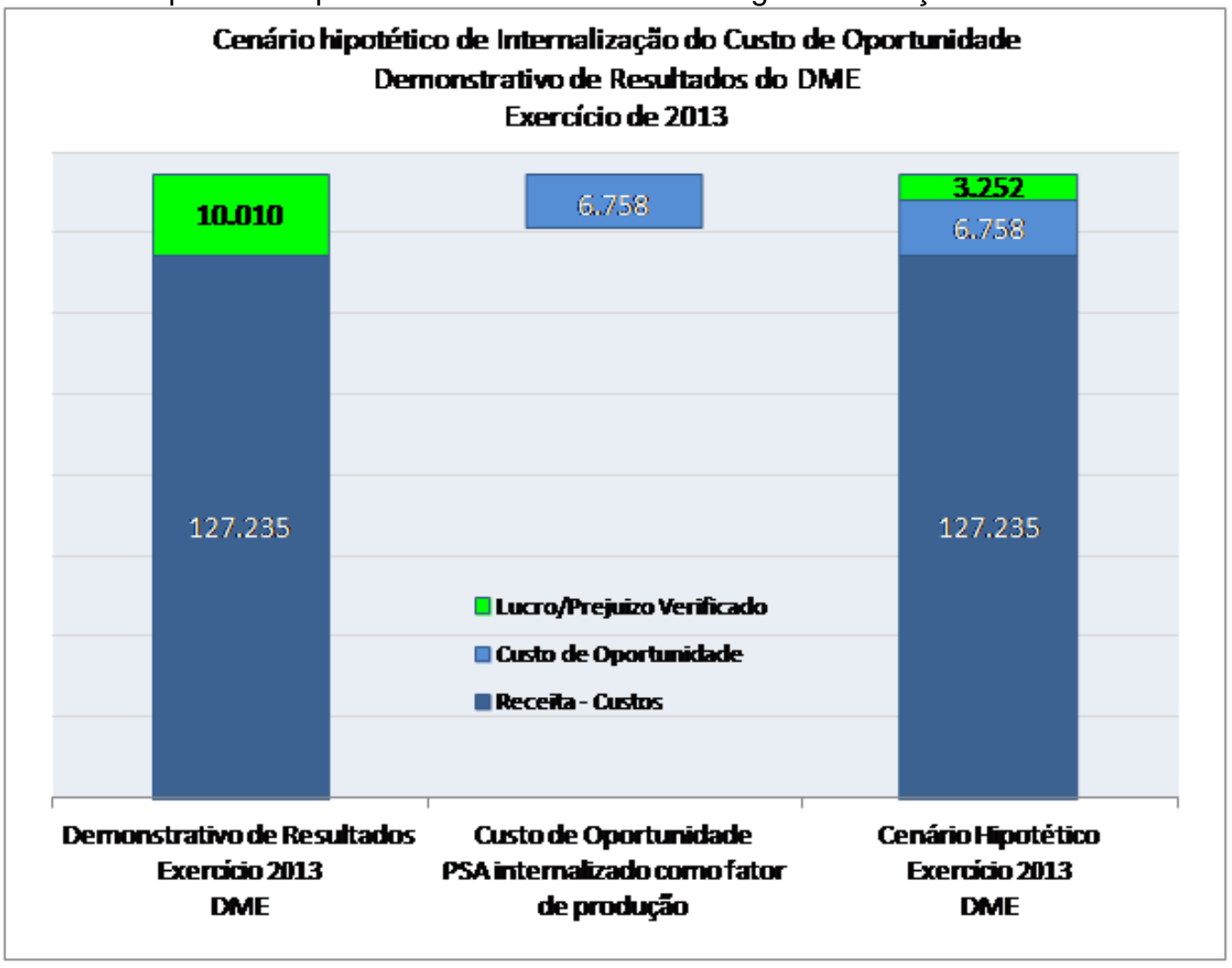

Figura 5 - Cenário hipotético de absorção do Custo de Oportunidade dos produtores pelo DMAE para PSA do manancial estratégicos de Poços de Caldas

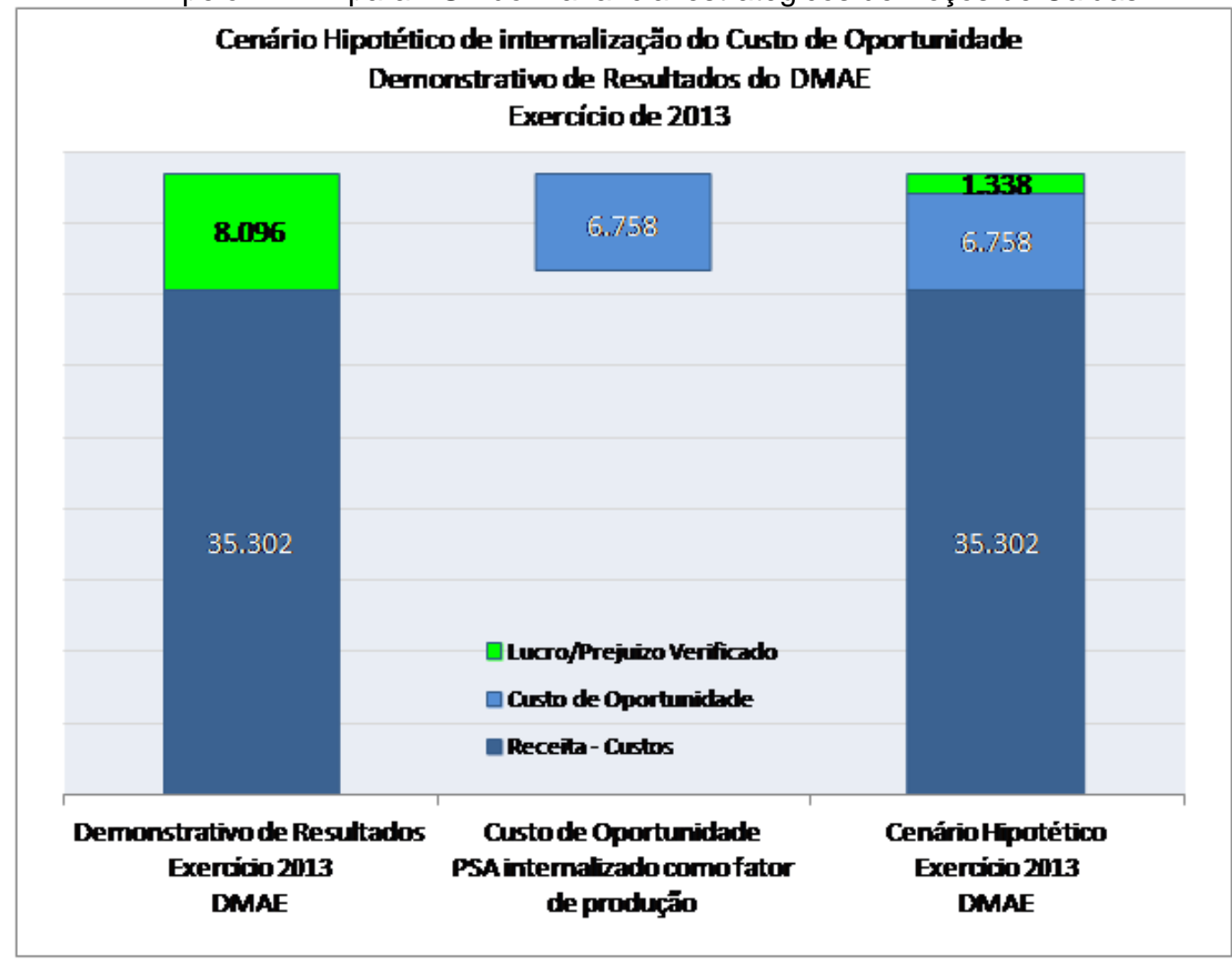


Figura 6 - Cenário hipotético de absorção do Custo de Oportunidade dos produtores pela soma do DME e DMAE para PSA do manancial estratégicos de Poços de Caldas

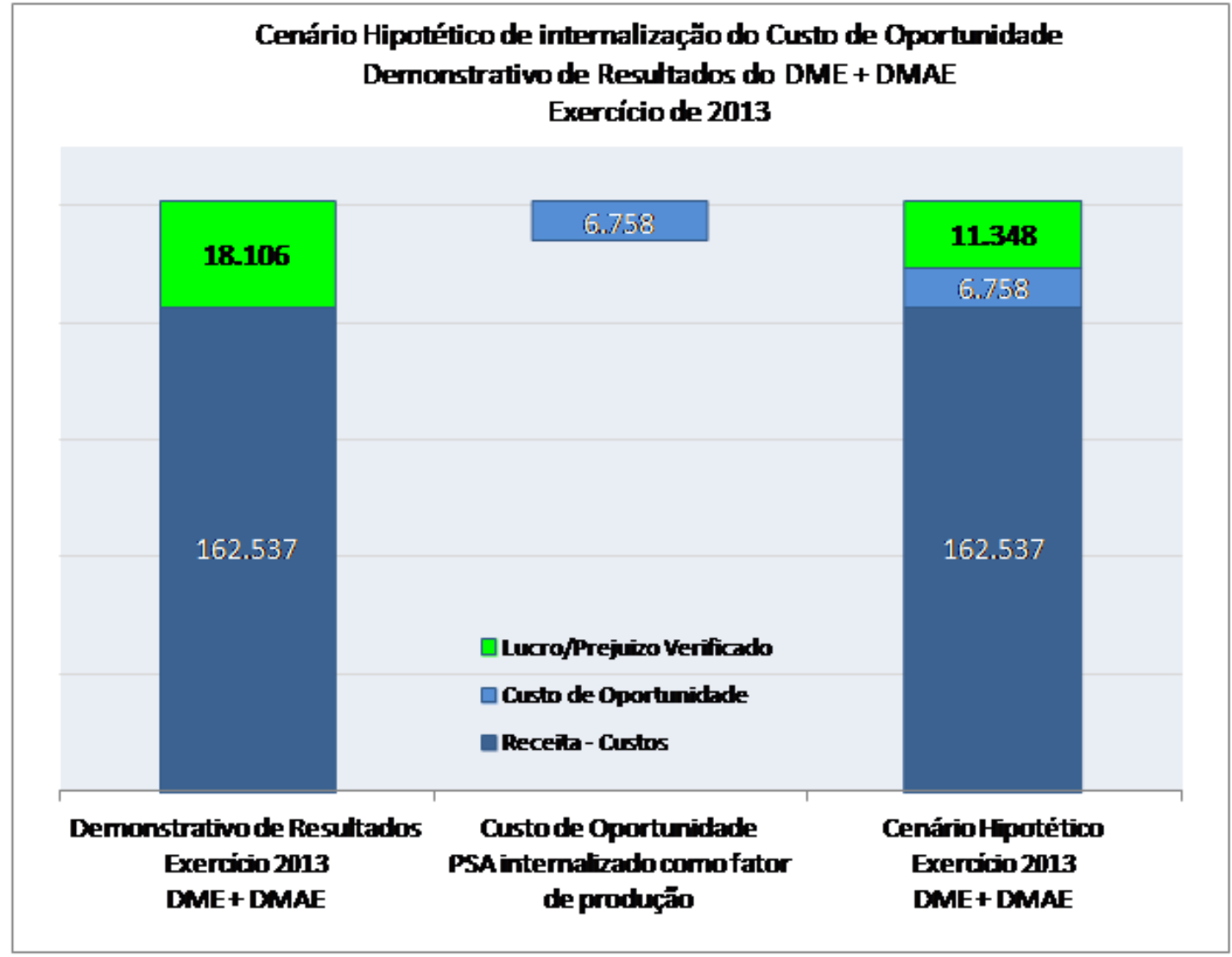

As simulações de cenários de resultados de PSA frente ao Custo de Oportunidade levam ao arranjo proposto nos Cenários 01 e 02 com $25 \%$ e $79 \%$ de valores respectivos frente ao custo de oportunidade. Tende-se a concluir que estes não seriam viáveis na perspectiva dos proprietários, porém, assim como nos Cenários 03 e 04 onde o custo é internalizado ou pelos empreendimentos com outorga ou pelos departamentos municipais, é preciso uma análise mais detalhada a partir dos princípios financeiros, contábeis e tributários assim como o envolvimento de todas as partes interessadas para que a decisão seja realizada de forma descentralizada e equilibrada como prevê a PNRH.

\section{CONCLUSÕES}

A importância estratégica da bacia hidrográfica do Ribeirão do Cipó como manancial de abastecimento de água potável no município de Poços de Caldas para atender a quase $50 \%$ da demanda e pelos demais usos na produção de energia e importante funcionalidade na composição de atrativo turístico do município. Reforça a importância do aprimoramento continuo do modelo de gestão de recursos hídricos do município, de forma que esta gestão possa acompanhar as peculiaridades dos usos múltiplos da água no município.

Concluiu-se a partir dos cenários econômicos hipotéticos que: de forma isolada, os resultados da DAP da população e a cobrança pelo uso da água outorgada no 
município aos moldes do que já se tem implementado na bacia do rio das Velhas, não são cenários atrativos economicamente para os proprietários frente ao custo de oportunidade.

Concluiu-se também que pela simulação de cenários que o PSA apresenta uma atratividade para os proprietários uma vez que o custo de oportunidade pode ser efetivado em um modelo de estável de retorno financeiro, porém, com impacto para os resultados financeiros dos empreendimentos outorgados e para os Departamentos de Água/Esgoto e Energia, principais usuários do recurso da bacia.

A partir das avaliações e cenários, foi possível concluir como viável economicamente a implantação do PSA na bacia do Ribeirão do Cipó, pelas diversas possibilidades existentes para internalização dos valores relacionados aos serviços ambientais dentro da econômica da bacia em comparação com o custo de oportunidade atual avaliado para os proprietários.

A utilização da metodologia de avaliação de cenários econômicos tendo como área de estudo uma bacia hidrográfica, demonstrou sua aplicabilidade, permitindo analises comparativas e correlações alinhadas às necessidades e características dos serviços ambientais providos pela bacia.

Por fim, no atual cenário e tendências do PSA no Brasil, pela complexidade da implantação da cobrança da água, pela ausência de metodologia consolidada para pagamento por serviços ambientais, este artigo permite a comparação de resultados obtidos por metodologias similares em bacias diferentes. Informações obtidas por diferentes abordagens distintas e particularizadas ao objeto de estudo, contribuindo assim com a divulgação, ampliação do uso e efetivação deste importante instrumento de gestão de recursos hídricos.

\section{REFERÊNCIAS}

ALBERTI, Heber Luiz Caponi. Caracterização fisiográfica e avaliação hidrológica na bacia do Ribeirão das Antas, Planalto de Poços de Caldas, MG. Dissertação de Mestrado - Universidade Estadual de Campinas. Instituto de Geociências Campinas, SP. 2008.

AEM - Millennium Ecossystem Assessment. Avaliação ecossistêmica do milênio. Disponível em: http://www.maweb.org/en/Sitemap.aspx Acesso em: 13 jun. 2014.

ANA - Agência Nacional de Águas (Brasil). O Balanço das águas, n. 3. Brasília, 2014.

ANA - Agência Nacional de Águas (Brasil). Balanço dos recursos hídricos 2013. Brasília, 2013.

ANEEL, Agência Nacional de Energia Elétrica (Brasil). Compensação financeira pela utilização de recursos hídricos para geração de energia elétrica - Brasília. 33 p. 2005 
BOYD, J; BANZHALF, S. What are Ecosystem Services? The Need for Standardized Environmental Accounting Units. Ecological Economics, v. 63 p.616-626, 2007. https://doi.org/10.1016/j.ecolecon.2007.01.002

BRASIL, Lei 9.433/97, de 8 de janeiro de 1997. Política nacional de recursos hídricos. Brasília: MMA, 2006.

BRASIL. Projeto de Lei no 792, de 2007. Projeto de Lei sobre serviços ambientais. Disponível em: http://www.camara.gov.br/sileg/integras/487093.pdf Acesso em: 06 fev. 2014.

CBH Mogi/Pardo. Comitê de Bacia Hidrográfica dos Afluentes Mineiros dos Rios Mogi-Guaçu e Pardo. Disponível em: http://www.cbhmogipardo.com.br/ Acesso em: 22 Jun. 2013.

CNS - CONSELHO NACIONAL DE SAÚDE. Resolução № 196, de 10 de outubro de 1996. Aprova as diretrizes e normas regulamentadoras de pesquisas envolvendo seres humanos. Disponível em:

http://conselho.saude.gov.br/web comissoes/conep/index.html. Acesso em: 06 fev. 2013.

COSTANZA, R. D`age. et al. The values of world`s ecosystem services and natural capital. Nature, v.387, p.253-260, 1997. https://doi.org/10.1038/387253a0

DMAE - Departamento Municipal de Água e Esgoto de Poços de Caldas.

Estatísticas. Disponível em: http://www.dmaepc.mg.gov.br. Acesso em: 01 Jun. 2014.

DMAE - Departamento Municipal de Agua e Esgoto de Poços de Caldas.

Demonstração das variações patrimoniais - exercício 2013. Disponível em: http://www.dmaepc.mg.gov.br/odmae/estatistica.php. Acesso em: 01jul. 2013.

DMAE - Departamento Municipal de Água e Esgoto de Poços de Caldas. Disponível em: http://www.dmaepc.mg.gov.br Acesso em: 01 de jun. 2014.

DME - Departamento Municipal de Energia de Poços de Caldas. Reservatórios, Represa Lindolpho Pio da Silva Dias (Barragem do Cipó). Disponível em: http://www.dme-pc.com.br/bv reservatorios.php. Acesso em: 06 de jul. 2013.

DME - Departamento Municipal de Energia de Poços de Caldas. Prestação de Contas DME distribuição S/A DMED. PAC 2013. Disponível em:

http://www.dmedsa.com.br. Acesso em: 11 jul. 2014.

DME - Departamento Municipal de Energia de Poços de Caldas. Especificações técnicas para elaboração de estudos ambientais para o processo de licença de instalação do alteamento do vertedouro da barragem do cipó. Disponível em http://www.dme-pc.com.br/arquivos/edital 1401890705 anexoiespecificacaotecnica.pdf Acesso maio de 2014 Acesso em: 10 maio 2014. 
DONG, Zhegju. et al. Computing payment for ecosystem services in watersheds: An analysis of the Middle Route Project of South-to-North Water Diversion in China. Journal of Environmental Sciences, v.23, p.2005-2012, 2011. https://doi.org/10.1016/S1001-0742(10)60663-8

ELKINGTON, John. Cannibals With forks. First Edition. U.K. Capstone Publishing Limited, Oxford. 1997. 407 p.

EMBRAPA - Empresa Brasileira de Pesquisa Agropecuária. Planilha de custo do cultivo de eucalipto. Disponível em:

http://www.cnpf.Embrapa.br/arquivos/Planilha Eucalipto.Pdf. Acesso em: 06 Maio 2014.

FISHER, B; TURNER, R. K. Ecosystem Services: Classification for Valuations.

Biological Conservation. v.141, p. 1167-1169, 2008.

https://doi.org/10.1016/j.biocon.2008.02.019

GIL, A. C. Métodos e técnicas de pesquisa social. 6. ed. São Paulo: Atlas, 2008. $200 \mathrm{p}$.

GROLLEAU G, MCCANN L. M. J. Designing watershed programs to pay farmers for water quality services: case studies of munich and new york city. Journal Elsevier Ecological Economics, Amsterdam, v. 76, p.87-94, Mar. 2012.

https://doi.org/10.1016/j.ecolecon.2012.02.006

HAU,J.L; BAKSHI,B.R. Promise and problems of emergy analyses. Ecological Modeling, v.178, p.215-225, October 2004.

https://doi.org/10.1016/j.ecolmodel.2003.12.016

HECKEN, Gert Van.; BASTIANENSEN, Johan.; VÁSQUEZ, William F.. The viability of local payments for watershed services: empirical evidence from Matiguás, Nicaragua. Ecological Economics, 74, p.169-176, 2012.

IBGE. Instituto Brasileiro de Geografia Estatística. Censo Demográfico 2010. Disponível em: http://www.ibge.gov.br/home/estatistica/populacao/censo2010 Acesso em: 06 jan. 2014. https://doi.org/10.1016/j.ecolecon.2011.12.016

IGAM - Instituto Mineiro de Gestão de Águas. Gestão das águas. Disponível em: http://www.igam.mg.gov.br/gestao-das-aguas. Acesso em: 19 jun. 2014.

IGAM - Instituto Mineiro de Gestão de Águas. Cobrança pelo uso da água Disponível em:

http://www.igam.mg.gov.br/gestao-das-aguas/cobranca-pelo-uso-de-recursoshidricos/1456-normativos-legais-sobre-a-cobranca-pelo-uso-da-agua. Acesso em: 19 jun. 2014.

INPE. Instituto Nacional de Pesquisas Espaciais. Catálogo de Imagens. Disponível em: http://imagens.dgi.inpe.br/. Acesso em: 27 de out. 2013.

KISHTAINY, Niall. et al. O livro da economia. Tradução Carlos S. Mendes Rosa. São Paulo: Globo, 2013. 
LIMA, Ana Paula Morais et al. Pagamento por serviços ambientais hídricos no Brasil: experiências iniciais e os desafios do monitoramento. Embrapa Solos. In: SIMPÓSIO BRASILEIRO DE RECURSOS HIDRÍCOS, 20., 2013. [Anais...]. Bento Gonçalves, RS, 2013.

MACHADO, F.H. Valoração econômica dos recursos hídricos da bacia hidrográfica do manancial do Ribeirão do Feijão São Carlos, SP. Dissertação (Mestrado em Meio Ambiente e Recursos Hídricos). Núcleo de Estudos Ambientais, Planejamento Territorial e Geomática - NEPA, Universidade Federal de Itajubá UNIFEI, Itajubá. MG, 2011.

MATTOS, Roberto de. Critérios para aplicação do programa produtor de água: estudo de caso no Alto Rio Grande, MG. Tese (Doutorado) - Universidade Federal de Lavras. UFLA.. 2009. 200p.

MOTTA, R. S. Manual para valoração econômica de recursos ambientais. Brasília. MMA.1998.218p.

VISION 2050: The new agenda for business. Disponível em: http://www.pfchange.org/wp-content/uploads/2013/05/Vision+2050+Full+Report.pdf Acesso em 17 de março de 2014.

PAGIOLA, Stefano; ARCENAS, Agustin e PLATAIS, Gunars. Can payments for environmental services help reduce poverty? an exploration of the issues and the evidence to date from latin america. World Development, v. 33, n. 2, p. 237-253. 2005. https://doi.org/10.1016/j.worlddev.2004.07.011

PEARCE, R. e TURNER, R.K. Economics of natural resource and the environment, The John Hopking University Press, Baltimore, 1990.

PLANO DIRETOR. Câmara Municipal de Poços de Caldas. Plano diretor do Município. Disponível em:

http://www.pocosdecaldas.mg.leg.br/legislacao/plano diretor/ Acesso em: 24 fev. 2014.

SUPRAM - Superintendência Regional de Regularização Ambiental. Parecer único Supram Sul Protocolo no 0013637/2012. Autoriza a construção do Barramento. Licenciamento Ambiental № 11381/2005/003/2010, 2012

TEJEIRO, Guillermo; STANTON Marcia. Sistemas estaduais de pagamento por serviços ambientais: diagnóstico, lições aprendidas e desafios para a futura legislação. São Paulo: Instituto O Direito por um Planeta Verde, 2014. 157p.

UNEP - United Nation Environmental Program. The economics of ecosystems and biodiversity. Disponível em: http://www.unep.org/. Acesso em: 24 fev. 2013.

WALLACE, K. J. Classification of ecosystem services: problems and solutions. biological conservation, 2007. https://doi.org/10.1016/.biocon.2007.07.015 
WUNDER, Sven.; ENGEL, Stefanie; PAGIOLA, Stefano. Taking stock: a comparative analysis of payments for environmental services programs in developed and developing countries. Ecological Economics, v.65 p. 834-852, 2008.

https://doi.org/10.1016/j.ecolecon.2008.03.010 